\title{
Computational modeling of the effects of autophagy on amyloid- $\beta$ peptide levels
}

Kyungreem $\mathrm{Han}^{1 *+}$, Soon Ho $\mathrm{Kim}^{2+}$ and MooYoung $\mathrm{Choi}^{2^{*}}$ (D)

\begin{abstract}
Background: Autophagy is an evolutionarily conserved intracellular process that is used for delivering proteins and organelles to the lysosome for degradation. For decades, autophagy has been speculated to regulate amyloid- $\beta$ peptide $(A \beta)$ accumulation, which is involved in Alzheimer's disease (AD); however, specific autophagic effects on the $A \beta$ kinetics only have begun to be explored.

Results: We develop a mathematical model for autophagy with respect to A kinetics and perform simulations to understand the quantitative relationship between $A \beta$ levels and autophagy activity. In the case of an abnormal increase in the $A \beta$ generation, the degradation, secretion, and clearance rates of $A \beta$ are significantly changed, leading to increased levels of $A \beta$. When the autophagic $A \beta$ degradation is defective in addition to the increased $A \beta$ generation, the $A \beta-$ regulation failure is accompanied by elevated concentrations of autophagosome and autolysosome, which may further clog neurons.

Conclusions: The model predicts that modulations of different steps of the autophagy pathway (i.e., A $\beta$ sequestration, autophagosome maturation, and intralysosomal hydrolysis) have significant step-specific and combined effects on the A $\beta$ levels and thus suggests therapeutic and preventive implications of autophagy in AD.
\end{abstract}

Keywords: Autophagy model, Amyloid- $\beta$ peptide, Alzheimer's disease

\section{Introduction}

Autophagy (from the Greek, autos, which means "self", and phagein, "to eat") is an evolutionarily conserved catabolic pathway, which delivers cytoplasmic constituents such as proteins and organelles to the lysosome for degradation and recycling [1-3]. Autophagy regulates protein quality, energy balance, and metabolic homeostasis, and furthermore it plays a role in the decision-making of cellular life and death, depending on the context of its activation [2-5]. The energy molecules and metabolic building blocks such as adenosine triphosphate (ATP) and amino acids, respectively, which are the recycled products of autophagy, regulate the consecutive steps of the autophagy process, i.e., sequestration (or autophagosome formation), autophagosome maturation (autolysosome formation), and intralysosomal hydrolysis, via mammalian target of

\footnotetext{
* Correspondence: kyungreem.han@nih.gov; mychoi@snu.ac.kr

${ }^{\dagger}$ Kyungreem Han and Soon Ho Kim contributed equally to this work.

${ }^{1}$ Laboratory of Computational Biology, National Heart, Lung and Blood Institute, National Institutes of Health, Bethesda, MD, USA

${ }^{2}$ Department of Physics and Astronomy and Center for Theoretical Physics, Seoul National University, Seoul, South Korea
}

rapamycin (mTOR) (for amino acids) and AMP-activated protein kinase (AMPK) pathways (for ATP) [6-9].

Neurons are especially vulnerable to autophagy dysfunction because they rely heavily upon autophagy for preventing the accumulation of toxic substances such as damaged proteins and protein aggregates [10-12]. For this, the brain is considered to be the most severely affected organ by the autophagy dysfunction [11, 12]: It is particularly related to the development of neurodegenerative disorders such as Alzheimer's disease (AD) and Parkinson's disease (PD) [10, 11, 13-17]. In young (healthy) neurons, autophagy can efficiently deliver the toxic substances along the unusually large architectures of axons and dendrites to lysosomes, which are concentrated in the cell body, while old (deteriorated) neurons have reduced autophagic degradation efficacy. It is becoming increasingly evident that the autophagic degradations of aggregate-prone proteins in neurons are highly substrate-selective [18]. These selective pathways appear to rely on the specific interactions between substrates and autophagy receptors/adaptors to sequester certain substrates within autophagosomes. Then the substrates proceed to the same degradation machinery

(c) The Author(s). 2020 Open Access This article is distributed under the terms of the Creative Commons Attribution 4.0 International License (http://creativecommons.org/licenses/by/4.0/), which permits unrestricted use, distribution, and 
as non-selective (bulk) autophagy [19-22]. Furthermore, it has been suggested that modulation of substrate-receptor/ adaptor interactions can be considered as a new therapeutic strategy for neurodegenerative disorders [18].

$\mathrm{AD}$, a common form of dementia, is one of the most prevalent neurological disorders associated with aging as its incidence is rapidly growing every year [23, 24]. The neuropathological hallmarks include deposition of extracellular plaques and formation of intracellular neurofibrillary tangles (NFTs). The plaques and NFTs predominantly consist of amyloid- $\beta$ peptides $(A \beta)$ and tau proteins, respectively. According to the amyloid hypothesis, an accumulation of $A \beta$ is the primary factor for the onset and progression of $\mathrm{AD}$ and the rest of the process including the NFT formation is the secondary effects of the $A \beta$ toxicity [25-27]. An increased intracellular $A \beta$ level is observed prior to the onset of extracellular plaque formation.

A $\beta$ consists of 36 to 43 amino acids and is intracellularly generated by specific proteolytic cleavage of the amyloid precursor protein (APP), an integral membrane protein which is concentrated in the synapses of neurons. An altered balance between generation, degradation, secretion (from the intra to the extracellular space of a neuron), and clearance (from the extracellular space) of $A \beta$ is responsible for the intracellular accumulation and extracellular plaque formation. It has been reported that the $A \beta$ generation rate is abnormally high in the early and late stages of $\mathrm{AD}$ [28]. $A \beta$ is degraded preferentially via autophagy; yet during late stages of $\mathrm{AD}$ autophagosomes fail to fuse with lysosomes [28]. In addition, the $A \beta$ secretion rate depends on the autophagy activity [29-31]: the secretion rate is reduced in mice lacking autophagy-related gene 7 (Atg7) [30]. On the other hand, the autophagic activity is influenced by the intracellular $A \beta$ concentration $[28,32-34]$. The $A \beta$ clearance rate in the extracellular space varies with the $A \beta$ concentration in a biphasic manner [35]. The AD patient is associated with a decrease in clearance by roughly $30 \%$, which may lead to toxic levels of $A \beta$ accumulation in the extracellular space over about 10 years [36].

Although many individual mechanisms have been studied for decades, the association of $A \beta$ kinetics with autophagy activity and the roles of autophagy in the pathogenesis of $\mathrm{AD}$ remain elusive. In this study, we develop a mathematical model for autophagy with respect to $A \beta$ kinetics, integrating various individual molecular and cellular data sets, in hope of providing a unified framework for understanding the complex dynamics between autophagy and $A \beta$ pathways. Simulations are performed to identify the quantitative relationship between autophagy activity and $A \beta$ kinetics, including the intra and extracellular levels, secretion, clearance, and autophagic degradation. This may provide a starting point for understanding the effects of autophagy on the pathogenesis of $\mathrm{AD}$ and implications of pharmacological autophagy modulation for AD therapy and prevention.

\section{Mathematical model}

The model assumes a four-compartment description of the autophagy process, including 1 ) intracellular protein (including normal/abnormal protein and intracellular $A \beta), 2)$ autophagosome, 3) autolysosome, and 4) extracellular A $\beta$ compartments (Fig. 1).

\section{Dynamic equations}

Intracellular proteins are classified as resident proteins S1 which conduct normal functions in a cell, abnormal proteins S2 including damaged proteins and those abnormally transcribed or translated, and amyloid- $\beta$ peptide S3. We write the equations for the dynamics of concentrations $C_{\mathrm{S} 1}, C_{\mathrm{S} 2}$, and $C_{\mathrm{S} 3}$ of $\mathrm{S} 1, \mathrm{~S} 2$, and $\mathrm{S} 3$, respectively, in the form:

$$
\begin{aligned}
& \frac{d C_{\mathrm{S} 1}}{d t}=(1-\alpha) R_{S}-\sigma C_{\mathrm{S} 1}-R_{g 1} C_{\mathrm{S} 1}-R_{d 1}-\beta C_{\mathrm{S} 1} \\
& \frac{d C_{\mathrm{S} 2}}{d t}=\alpha R_{S}+\sigma C_{\mathrm{S} 1}-R_{g 2} C_{\mathrm{S} 2}-R_{d 2}, \\
& \frac{d C_{\mathrm{S} 3}}{d t}=\beta C_{\mathrm{S} 1}-R_{g 3} C_{\mathrm{S} 3}-R_{d 3}-R_{s e c} C_{\mathrm{S} 3}
\end{aligned}
$$

where $R_{S}$ represents the (total) protein synthesis rate (from DNA) and $\alpha$ is the fraction of S2, namely, S1 and $\mathrm{S} 2$ are produced at the rates of $(1-\alpha) R_{S}$ and $\alpha R_{S}$, respectively. $\sigma$ is the rate constant for deterioration of $\mathrm{S} 1$ (i.e., transformation from $\mathrm{S} 1$ to $\mathrm{S} 2$ ). $R_{g i}$ and $R_{d i}$ represent the specific rates of autophagosome formation and the non-autophagic degradation of $\mathrm{Si}$ (for $\mathrm{i}=1,2$, and 3), respectively. $\beta$ denotes the rate constant for $\mathrm{A} \beta$ generation and $R_{s e c}$ is the $\mathrm{A} \beta$ secretion specific rate from the intra to the extracellular space.

The dynamics of the $A \beta$ concentration in the extracellular space $C_{\mathrm{ES} 3}$ reads:

$$
\frac{d C_{\mathrm{ES} 3}}{d t}=R_{s e c} C_{\mathrm{S} 3}-R_{c l r} C_{\mathrm{ES} 3},
$$

where $R_{c l r}$ denotes the specific clearance rate for $\mathrm{A} \beta$ in the extracellular space.

Variations of the intracellular autophagosome concentration with time are determined by the difference between the autophagosome formation specific rate $R_{g i}$ and the autolysosome formation specific rate $R_{l i}(i=1,2$, and 3 for S1, S2, and S3, respectively). With $C_{\mathrm{gi}}$ denoting the concentration of autophagosome originating from $\mathrm{Si}$ $(i=1,2$, and 3 ), the dynamics of the concentration is governed by the following equation:

$$
\frac{d C_{\mathrm{gi}}}{d t}=R_{g i} C_{\mathrm{Si}}-R_{l i} C_{\mathrm{gi}} .
$$

The intracellular concentration $C_{\text {li }}$ of autolysosomes originating from $\mathrm{Si}(\mathrm{i}=1,2$, and 3 ) is determined by the difference between $R_{l i}$ and the intralysosomal hydrolysis 


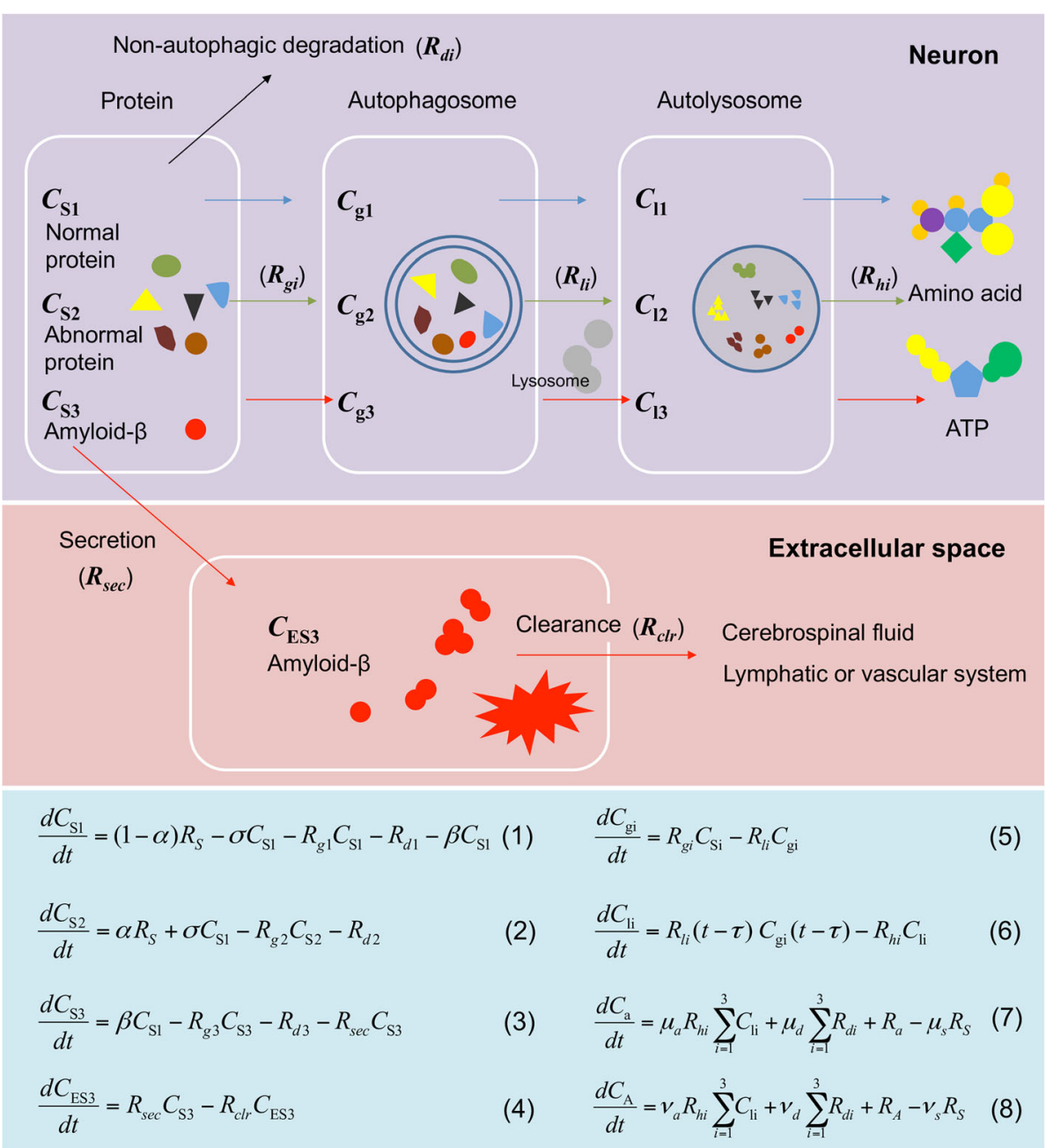

Fig. 1 Schematic diagram of the model system. The rounded rectangles with white borders illustrate four compartments: 1) intracellular protein, 2) autophagosome, 3) autolysosome, and 4) extracellular amyloid- $\beta(A \beta)$ peptide. $C_{S 1}, C_{S 2}$ and $C_{S 3}$ denote the concentrations of intracellular resident protein $S 1$, abnormal protein $S 2$, and amyloid- $\beta$ peptide $S 3$, respectively. $C_{g i}$ and $C_{l i}$ represent the concentrations of autophagosomes and autolysosomes, respectively, from $\mathrm{Si}(\mathrm{i}=1,2,3)$. $C_{\mathrm{ES} 3}$ stands for the extracellular A $\beta$ concentration. $R_{g i} R_{l i}, R_{h i}$ and $R_{d i}$ are the specific rates of autophagosome formation, autolysosome formation, intralysosomal hydrolysis, and non-autophagic degradation, respectively, for $\mathrm{Si}(i=1,2$, and 3 again). $R_{\text {sec }}$ and $R_{c l}$ denote respectively the rates of $A \beta$ secretion and clearance. The differential equations describe variations of the concentrations of proteins (Eqs. (1)-(4)), autophagosomes (Eq. (5)), autolysosomes (Eq. (6)), amino acids (Eq. (7)), and ATP (Eq. (8))

specific rate $R_{h i}(i=1,2$, and 3$)$. The equation governing the dynamics takes the form:

$$
\frac{d C_{\mathrm{li}}}{d t}=R_{l i}(t-\tau) C_{\mathrm{gi}}(t-\tau)-R_{h i} C_{\mathrm{li}}
$$

Note that the autolysosome concentration at time $t$ is affected by the autophagosome concentration at time $t-$ $\tau$, earlier by the delay time $\tau$, which is taken to be $8 \mathrm{~min}$ ( $\tau=480 \mathrm{~s})$ [37-39].

The dynamics of intracellular amino acids, the concentration of which is denoted by $C_{\mathrm{a}}$ reads:

$$
\frac{d C_{\mathrm{a}}}{d t}=\mu_{a} R_{h i} \sum_{i=1}^{3} C_{\mathrm{li}}+\mu_{d} \sum_{i=1}^{3} R_{d i}+R_{a}-\mu_{s} R_{S}
$$

The first and second terms on the right-hand side correspond to the supply of amino acids due to the autophagic intralysosomal hydrolysis and non-autophagic protein degradation, respectively, with appropriate constants $\mu_{a}$ and $\mu_{d}$ describing the average numbers of amino acids produced from autophagic and nonautophagic degradation, respectively. The third term represents the rate of amino acid supply from extracellular fluid into cells that is assumed to be 
proportional to the metabolic demand (i.e., protein synthesis rate $R_{S}$ ) and the loss of protein (i.e., secretion rate of $\mathrm{A} \beta$, given by $\left.R_{s e c} C_{\mathrm{S} 3}\right)$ such that $R_{a}=$ $\mu_{c} R_{S}+\mu_{\beta} R_{s e c} C_{\mathrm{S} 3}$ with appropriate constants $\mu_{c}$ and $\mu_{\beta}$. The last term describes the reduction of amino acids due to protein synthesis with the constant $\mu_{s}$, the average number of amino acids in a protein molecule.

The dynamic equation for intracellular ATP concentration $C_{\mathrm{A}}$ reads:

$$
\frac{d C_{\mathrm{A}}}{d t}=v_{a} R_{h i} \sum_{i=1}^{3} C_{\mathrm{li}}+v_{d} \sum_{i=1}^{3} R_{d i}+R_{A}-v_{s} R_{S}
$$

where $v_{a}$ and $v_{d}$ are the average numbers of ATP molecules produced from autophagic degradation and from non-autophagic degradation, respectively. The net intracellular ATP generation rate $R_{A}$ is assumed to be $R_{A}=v_{c} R_{S}+v_{\beta} R_{s e c} C_{\mathrm{S} 3}$ that is associated with the metabolic demand and the loss of protein, with appropriate constants $v_{c}$ and $v_{\beta}$. The last term corresponds to the reduction of ATP due to protein synthesis, where $v_{s}$ gives the average number of ATP molecules in a protein.

$\mathrm{n}$ average protein molecule in a cell is assumed to be composed of 500 amino acid residues; in other words, 500 amino acids are consumed in unit protein synthesis (i.e., $\mu_{s}=500$ ). Considering that elongation of one amino acid during translation requires approximately four ATP molecules, we have assumed that 2000 ATP molecules are required for the synthesis of a protein $\left(v_{s}=2000\right)$. However, the numbers of amino acids and ATP molecules per degradation of one protein via autophagic or non-autophagic protein degradation have been set to be less than those required in the protein synthesis, because the efficacy of protein recycling is expected to be less than $100 \%$; this yields $\mu_{a}=\mu_{d}=\mu_{\beta}=v_{a}=v_{d}=v_{\beta}=300$, $\mu_{c}=200$, and $v_{c}=1700$.

Details of the autophagy-related rates in Eqs. (1) to (8) are given in the following subsections. The parameters are summarized in Table 1.

\section{Autophagosome formation}

We take the autophagosome formation specific rates $R_{g i}$ from $\mathrm{Si}$ (for $\mathrm{i}=1,2$, and 3), which depend on the intracellular concentrations $C_{\mathrm{S} 3}$ of $\mathrm{A} \beta[28,32-34], C_{\mathrm{A}}$ of ATP [40, 41] , and $C_{\mathrm{a}}$ of amino acids [42] as follows:

$$
\begin{aligned}
& R_{g 1}\left(C_{\mathrm{S} 3}, C_{\mathrm{a}}, C_{\mathrm{A}}\right)=r_{g 1}\left(\omega_{g} C_{\mathrm{S} 3}{ }^{\zeta}+\psi_{g} C_{\mathrm{S} 3}+1\right) \\
& \frac{C_{\mathrm{A}}{ }^{4}}{C_{\mathrm{A}}{ }^{4}+k_{g}{ }^{4}} \frac{p_{g}{ }^{12}}{C_{\mathrm{A}}{ }^{12}+p_{g}{ }^{12}} \frac{a_{g}{ }^{8}}{C_{\mathrm{a}}{ }^{8}+a_{g}{ }^{8}}\left(1+\gamma_{g} e^{-\xi_{g} C_{\mathrm{a}}}\right),
\end{aligned}
$$

$$
\begin{aligned}
& R_{g 2}\left(C_{\mathrm{S} 3}, C_{\mathrm{a}}, C_{\mathrm{A}}\right)=r_{g 2}\left(\omega_{g} C_{\mathrm{S} 3} \zeta_{g}+\psi_{g} C_{\mathrm{S} 3}+1\right) \\
& \frac{C_{\mathrm{A}}{ }^{4}}{C_{\mathrm{A}}{ }^{4}+k_{g}{ }^{4}} \frac{p_{g}{ }^{12}}{C_{\mathrm{A}}{ }^{12}+p_{g}{ }^{12}}\left(1+\gamma_{g} e^{-\xi_{g} C_{\mathrm{a}}}\right), \\
& R_{\mathrm{g} 3}\left(C_{\mathrm{S} 3}, C_{\mathrm{a}}, C_{\mathrm{A}}\right)=r_{g 3}\left(\omega_{g} C_{\mathrm{S} 3}{ }^{\zeta_{g}}+\psi_{g} C_{\mathrm{S} 3}+1\right) \\
& \frac{C_{\mathrm{A}}{ }^{4}}{C_{\mathrm{A}}{ }^{4}+k_{g}{ }^{4}} \frac{p_{g}{ }^{12}}{C_{\mathrm{A}}{ }^{12}+p_{g}{ }^{12}}\left(1+\gamma_{g} e^{-\xi_{g} C_{\mathrm{a}}}\right),
\end{aligned}
$$

where $r_{g i}$ is the rate constant for autophagosome formation from $\mathrm{Si}$ (for $\mathrm{i}=1,2$, and 3), with appropriate constants $\omega_{g}, \zeta_{g}, \psi_{g}$ (for A $\beta$ ), $k_{g}, p_{g}$ (ATP), $a_{g}, \gamma_{g}$, and $\xi_{g}$ (amino acids).

Intracellular $A \beta$ affects the mTOR signaling, which negatively regulates autophagy induction, exhibiting a nonlinear relationship: The mTOR activity increases (i.e., suppressing autophagosome formation) with the $A \beta$ level until reaching a certain threshold $(\sim 0.5 \mu \mathrm{M})$ and then the activity gradually decreases (restoring autophagosome formation) above the threshold concentration $[28,32-34]$. This nonlinear relationship has been included in Eqs. (9)-(11) as a simple algebraic equation in the form of $\omega_{g} C_{\mathrm{S} 3}{ }_{g}+\psi_{g} C_{\mathrm{S} 3}+1$.

The remaining part of the right-hand side contains the ATP and amino acid dependency of the autophagosome formation step. Under normal conditions, it appears that S2 and S3, abnormal proteins and $A \beta$, are preferentially degraded by autophagy. However, as the intracellular energy/nutrient reduces due to, e.g., starvation or increased metabolic demand, all the proteins (S1, S2 and S3) are degraded non-selectively for the rapid supply of essential energy molecules (e.g., ATP) and metabolic building blocks (i.e., amino acids) [21, 22, 43, 44]. Therefore, it is assumed in this model that the autophagosome formation rate from resident proteins $\mathrm{S} 1$, which is lower than that from abnormal proteins and $A \beta$ (S2 and S3) under normal conditions, becomes gradually equal to those of S2 and S3 as the amino acid concentration is decreased [45-48].

\section{Autolysosome formation and intralysosomal hydrolysis}

The autolysosome formation specific rate $R_{l i}$ reads $(i=1$, 2, and 3 for S1, S2, and S3)

$$
R_{l i}\left(C_{\mathrm{A}}\right)=r_{l i} \frac{C_{\mathrm{A}}{ }^{4}}{C_{\mathrm{A}}{ }^{4}+k_{l}{ }^{4}} \frac{p_{l}^{12}}{C_{\mathrm{A}}{ }^{12}+p_{l}^{12}},
$$

where $r_{l i}$ denotes the rate constant for autolysosome formation from $\mathrm{Si}$ with appropriate constants $k_{l}$ and $p_{l}$ for ATP, based on biological experiments [40, 41]. 
Table 1 Parameters in computer simulations

\begin{tabular}{|c|c|c|c|}
\hline Parameter & Value & Unit & Description \\
\hline$r_{g i}^{(0)}$ & $1.12 \times 10^{-5}$ & $\mathrm{~s}^{-1}$ & Rate constant for autophagosome formation of $\mathrm{Si}(\mathrm{i}=1,2,3)$ (normal value) \\
\hline a & $1.00 \times 10^{-2}$ & (unitless) & Fraction of $\mathrm{S} 2$ in protein synthesis rate $R_{S}$ \\
\hline$\beta^{(0)}$ & $5.56 \times 10^{-10}$ & $s^{-1}$ & Rate constant for $A \beta$ generation (normal value) \\
\hline$\sigma$ & $4.00 \times 10^{-7}$ & $s^{-1}$ & Rate constant for deterioration of S1 \\
\hline$\omega_{g}$ & $-9.43 \times 10^{-1}$ & $\mathrm{mM}^{-0.1}$ & $\begin{array}{l}\text { Constant for autophagosome formation } \\
\text { (A } \mathrm{B} \text { dependency) }\end{array}$ \\
\hline$\zeta_{g}$ & $1.00 \times 10^{-1}$ & (unitless) & $\begin{array}{l}\text { Constant for autophagosome formation } \\
\text { (Aß dependency) }\end{array}$ \\
\hline$\psi_{g}$ & $1.01 \times 10^{2}$ & $\mathrm{mM}^{-1}$ & $\begin{array}{l}\text { Constant for autophagosome formation } \\
\text { (A } \beta \text { dependency) }\end{array}$ \\
\hline$k_{g}$ & 2.83 & $\mathrm{mM}$ & $\begin{array}{l}\text { Constant for autophagosome formation } \\
\text { (ATP dependency) }\end{array}$ \\
\hline$p_{g}$ & 3.00 & $\mathrm{mM}$ & $\begin{array}{l}\text { Constant for autophagosome formation } \\
\text { (ATP dependency) }\end{array}$ \\
\hline$a_{g}$ & 4.50 & $\mathrm{mM}$ & $\begin{array}{l}\text { Constant for autophagosome formation } \\
\text { (amino acids dependency) }\end{array}$ \\
\hline$\gamma_{g}$ & 1.22 & (unitless) & $\begin{array}{l}\text { Constant for autophagosome formation } \\
\text { (amino acids dependency) }\end{array}$ \\
\hline$\xi_{g}$ & $7.49 \times 10^{-2}$ & $\mathrm{mM}^{-1}$ & $\begin{array}{l}\text { Constant for autophagosome formation } \\
\text { (amino acids dependency) }\end{array}$ \\
\hline$r_{l i}^{(0)}$ & $2.47 \times 10^{-5}$ & $s^{-1}$ & Rate constant for autolysosome formation of $\mathrm{Si}(\mathrm{i}=1,2,3)$ (normal value) \\
\hline$k_{l}$ & 2.83 & $\mathrm{mM}$ & $\begin{array}{l}\text { Constant for autolysosome formation } \\
\text { (ATP dependency) }\end{array}$ \\
\hline$p_{l}$ & 3.00 & $\mathrm{mM}$ & $\begin{array}{l}\text { Constant for autolysosome formation } \\
\text { (ATP dependency) }\end{array}$ \\
\hline$r_{h i}^{(0)}$ & $1.39 \times 10^{-5}$ & $s^{-1}$ & Rate constant for intralysosomal hydrolysis of $\mathrm{Si}(\mathrm{i}=1,2,3)$ (normal value) \\
\hline$\delta_{h}$ & $7.24 \times 10^{-1}$ & (unitless) & $\begin{array}{l}\text { Exponent for intralysosomal hydrolysis } \\
\text { (ATP dependency) }\end{array}$ \\
\hline$k_{h}$ & 2.99 & $\mathrm{mM}$ & $\begin{array}{l}\text { Constant for intralysosomal hydrolysis } \\
\text { (ATP dependency) }\end{array}$ \\
\hline$r_{s}$ & $1.48 \times 10^{-5}$ & $\mathrm{mM} \cdot \mathrm{s}^{-1}$ & Rate constant for protein/organelle synthesis \\
\hline$k_{5}$ & $1.77 \times 10^{1}$ & $\mathrm{mM}$ & $\begin{array}{l}\text { Constant for protein/organelle synthesis } \\
\text { (amino acids dependency) }\end{array}$ \\
\hline$C_{A}^{(m)}$ & 3.00 & $\mathrm{mM}$ & ATP concentration corresponding to maximal protein/organelle synthesis rate \\
\hline$r_{\mathrm{sec}}$ & $4.67 \times 10^{-9}$ & $s^{-1}$ & Rate constant for $A \beta$ secretion \\
\hline$r_{c l r}$ & $2.23 \times 10^{-1}$ & $\mathrm{mM}^{-1} \cdot \mathrm{s}^{-1}$ & Rate constant for $A \beta$ clearance \\
\hline$\omega_{\text {ext }}$ & $6.34 \times 10^{-5}$ & $\mathrm{mM}$ & Rate constant for $A \beta$ clearance \\
\hline
\end{tabular}

The intralysosomal hydrolysis specific rate $R_{h i}$ is taken as a function of the intracellular ATP concentration $(i=$ $1,2$, and 3$)$ :

$$
R_{h i}\left(C_{\mathrm{A}}\right)=r_{h i} \frac{C_{\mathrm{A}}^{\delta_{h}}}{C_{\mathrm{A}}^{\delta_{h}}+k_{h}{ }^{\delta_{h}}},
$$

with appropriate exponent $\delta_{h}$ and constant $k_{h}$ for ATP, where $r_{h i}$ is the rate constant for intralysosomal hydrolysis [40, 41]. Further details of the equations for autolysosome formation and intralysosomal hydrolysis can be found in literature $[4,9,49,50]$.

\section{Secretion and clearance of amyloid- $\beta$}

Considering that $A \beta$ secretion from the intra to extra cellular space of a neuron is positively correlated with the autophagy induction level [29-31], we assume the A $\beta$ secretion specific rate $R_{s e c}$ to be proportional to the degree of amino acid- and ATP-dependent 
autophagosome induction, as defined in Eqs. (9)-(11), with an appropriate constant $r_{s e c}$ :

$$
R_{s e c}\left(C_{\mathrm{a}}, C_{\mathrm{A}}\right)=r_{s e c} \frac{C_{\mathrm{A}}{ }^{4}}{C_{\mathrm{A}}{ }^{4}+k_{g}{ }^{4}} \frac{p_{g}{ }^{12}}{C_{\mathrm{A}}{ }^{12}+p_{g}{ }^{12}}\left(1+\gamma_{g} e^{-\xi_{g} C_{\mathrm{a}}}\right)
$$

The concentration-dependent biphasic $A \beta$ clearance rate $R_{c l r}$ in the extracellular space is assumed, on the basis of biological experiments $[35,36,51]$, to take the form:

$$
R_{c l r}\left(C_{\mathrm{ES} 3}\right)=r_{c l r}\left(C_{\mathrm{ES} 3}+\omega_{\text {ext }}\right),
$$

where $r_{c l r}$ denotes the rate constant for $\mathrm{A} \beta$ clearance, with an appropriate constant $\omega_{\text {ext }}$. The rate of $A \beta$ clearance varies with the concentration according to the measurement on Alzheimer's mouse model [35]: While the half-life is very short at high concentrations of extracellular $A \beta$, it grows longer as the concentration decreases. Equation (15) captures qualitatively this biphasic nature of $A \beta$ clearance [35] and its value lies within a reasonable range consistent with the state-of-the-art measurements [36, 51].

\section{Protein synthesis and non-autophagic degradation}

The (total) protein synthesis rate $R_{S}$ which depends on intracellular concentrations $C_{\mathrm{a}}$ of amino acids and $C_{\mathrm{A}}$ of ATP reads [52].

$$
R_{S}\left(C_{\mathrm{a}}, C_{\mathrm{A}}\right)= \begin{cases}r_{s} \frac{C_{\mathrm{a}}}{C_{\mathrm{a}}+k_{s}} \frac{\exp \left[C_{\mathrm{A}}\right]-1}{\exp \left[C_{\mathrm{A}}^{(m)}\right]-1} & \text { for } C_{\mathrm{A}}<C_{\mathrm{A}}^{(m)} \\ r_{s} \frac{C_{\mathrm{a}}}{C_{\mathrm{a}}+k_{s}} & \text { for } C_{\mathrm{A}} \geq C_{\mathrm{A}}^{(m)}\end{cases}
$$

with appropriate constant $k_{s}$ for amino acid, where $C_{\mathrm{A}}^{(m)}$ is the ATP concentration corresponding to the maximal protein synthesis rate and $r_{s}$ denotes the rate constant for the protein synthesis. Further details of the protein synthesis can be found in literature [4, 9, 49, 50].

The non-autophagic protein degradation machinery such as the ubiquitin-proteasome system has been considered in the model. We assume that the amount of protein degradation by autophagy constitutes $80 \%$ of the total amount of protein degradation and the non-autophagic protein degradation machinery is responsible for the remaining 20\% [53]. Accordingly, we take the rate of non-autophagic degradation $R_{d i}(i=1,2$, and 3$)$ to be $25 \%$ of autophagic degradation:

$$
R_{d i}=\frac{1}{4} R_{h i} C_{\mathrm{li}}
$$

\section{Results}

$A \beta$ kinetics under normal and pathological conditions In Fig. 2, the relation of intracellular $\left(C_{\mathrm{S} 3}\right)$ and extracellular $\left(C_{\mathrm{ES} 3}\right) \mathrm{A} \beta$ levels with the respective $\mathrm{A} \beta$ fluxes under normal conditions (i.e., for basal parameter values) are shown, providing kinetic and dynamic insights into the $A \beta$ regulation. As illustrated in Fig. 1, $C_{\mathrm{S} 3}$ (the second row of the first column) is determined by the difference between influx (i.e., $A \beta$ generation flux, denoted by $F_{\text {gen }}$, the concentration of $\mathrm{A} \beta$ generated per unit time given in units of $\mathrm{mM} / \mathrm{s}$ ) and efflux rates such as autophagic sequestration $F_{\text {seq }}$ (the concentration of intracellular $\mathrm{A} \beta$ sequestered into autophagosomes per unit time, i.e., $F_{\text {seq }}=R_{g 3} C_{\mathrm{S} 3}$ ), non-autophagic degradation $F_{\text {nap }}$ (the concentration of intracellular $\mathrm{A} \beta$ degraded via the non-autophagic mechanism per unit time, i.e., $F_{\text {nap }}=$ $R_{d 3}$ ), and secretion $F_{s e c}$ (the concentration of intracellular $\mathrm{A} \beta$ secreted from the inside to outside of a neuron per unit time, i.e., $F_{s e c}=R_{s e c} C_{\mathrm{S} 3}$ ). $C_{\mathrm{ES} 3}$ (the third row of the second column) is governed by $F_{\text {sec }}$ and the clearance flux $F_{c l r}$ (the concentration of $\mathrm{A} \beta$ removed from the extracellular space per unit time, i.e., $\left.F_{c l r}=R_{c l r} C_{\mathrm{ES} 3}\right)$.

Figures 3 and 4 compare values of $C_{\mathrm{S} 3}$ and $C_{\mathrm{ES} 3}$, respectively, under the normal, early stage (i.e., abnormal increase in $\mathrm{A} \beta$ generation), and late stage $\mathrm{AD}$ (i.e., increased $A \beta$ generation together with decreased autophagic lysosomal degradation) conditions [28]. The simulations have been performed with the basal value $\beta^{(0)}$ of the $A \beta$ generation rate constant, i.e., $\beta=\beta^{(0)}$, for the normal condition, while data for the early and late stage AD conditions have been obtained at an extremely high $A \beta$ generation rate, $\beta=100 \times \beta^{(0)}$. Further, in the late stage case, the specific rate constants of autolysosome formation and intralysosomal hydrolysis have been set to be $10 \%$ of the basal values, i.e., $r_{l 3}=$ $0.1 \times r_{l 3}{ }^{(0)}$ and $r_{h 3}=0.1 \times r_{h 3}{ }^{(0)}$.

It is observed that $C_{\mathrm{S} 3}$ and $C_{\mathrm{ES} 3}$ are significantly higher in $\mathrm{AD}$ conditions than in the basal condition $-C_{\mathrm{S} 3}$ is higher at the early stage than at the late stage AD (Fig. 3) while $C_{\mathrm{ES} 3}$ is higher at the late stage $\mathrm{AD}$ (Fig. 4). In both pathological conditions, autophagy induction (i.e., a 20 -fold increase in the autophagosome formation rate constant: $\left.r_{g 3}=20 \times r_{g 3}{ }^{(0)}\right)$ significantly reduces $C_{\mathrm{S} 3}$ and $C_{\mathrm{ES} 3}$. In addition, the early and late stage $\mathrm{AD}$ exhibit asymmetric oscillating patterns. $C_{\mathrm{S} 3}$ increases gradually and then drops rapidly; conversely, $C_{\mathrm{ES} 3}$ increases rapidly and drops gradually. Under the basal condition they exhibit relatively symmetrical oscillation patterns.

Both $\mathrm{A} \beta$ secretion flux $F_{s e c}$ and clearance flux $F_{c l r}$ are significantly promoted in the early and late stage $\mathrm{AD}$ cases compared to those in the basal condition (the first column of Fig. 5). The peaks of $F_{s e c}$ in early $\mathrm{AD}$ are sharper and higher but stay at the near-zero rate for a longer period than in late AD. In contrast, $F_{c l r}$ exhibits higher peaks in late $\mathrm{AD}$ than in early $\mathrm{AD}$. Autophagy induction (i.e., $r_{g 3}=$ $\left.20 \times r_{g 3}{ }^{(0)}\right)$ significantly reduces those fluxes, close to the basal levels. 

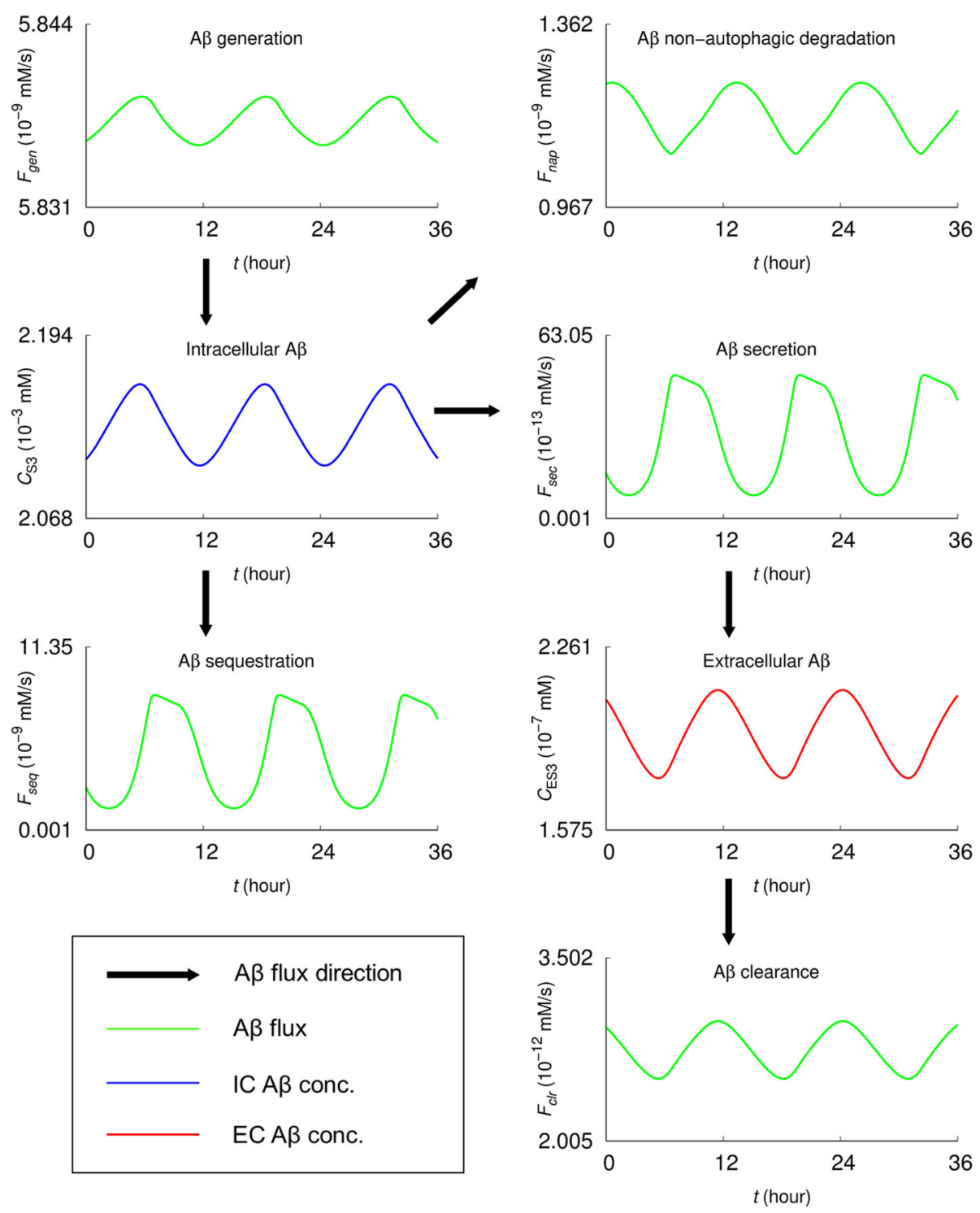

Fig. 2 The basal steady-state $A \beta$ concentrations and fluxes. $C_{S 3}$ and $C_{E S 3}$ represent the concentrations of intracellular (IC) and extracellular (EC) $A \beta$, respectively. $F_{\text {gen, }} F_{\text {seq, }}$ and $F_{\text {nap }}$ denote the $A \beta$ generation, sequestration (the first step of autophagic degradation, i.e., autophagosome formation), and non-autophagic degradation fluxes, respectively; $F_{\text {sec }}$ and $F_{c l r}$ the secretion (from the IC to the EC space) and A $\beta$ clearance (in the EC space)

fluxes, respectively

In what follows, autophagy dynamics corresponding to the normal and $\mathrm{AD}$ conditions are presented, including steady-state concentrations of autophagosome, autolysosome, and autophagic fluxes.

\section{Dynamics of autophagy and implications in the $A \beta$ regulations}

Protein sequestration (i.e., autophagosome formation) flux $F_{\text {seq, }}$, autophagosome maturation (i.e., autolysosome formation) flux $F_{\text {mat }}$, and intralysosomal hydrolysis flux $F_{h y d}$ in both early and late stage AD are significantly increased compared with those on the basal condition (the first, third, and fifth rows of
Fig. 6). The peaks of $F_{\text {seq }}$ and $F_{\text {mat }}$ in early stage AD are sharper and higher than those in the late stage. The steady-state concentrations of autophagosomes and autolysosomes, $C_{\mathrm{g} 3}$ and $C_{\mathrm{l} 3}$, in the $\mathrm{AD}$ cases are greater than those in the basal condition case: the values at the late stage of $\mathrm{AD}$ are about ten times greater than those at the early stage (the second and fourth rows of Fig. 6).

In the cases of early and late stage $\mathrm{AD}$, autophagy induction (i.e., $r_{g 3}=20 \times r_{g 3}{ }^{(0)}$ ) significantly decreases $F_{\text {seq }}$ and $F_{\text {mat }}$, while it increases $F_{\text {hyd }}$ (the first, third, and fifth rows of the second and third columns of Fig. 6). The steadystate autophagosome concentration $C_{\mathrm{g} 3}$ is decreased while 

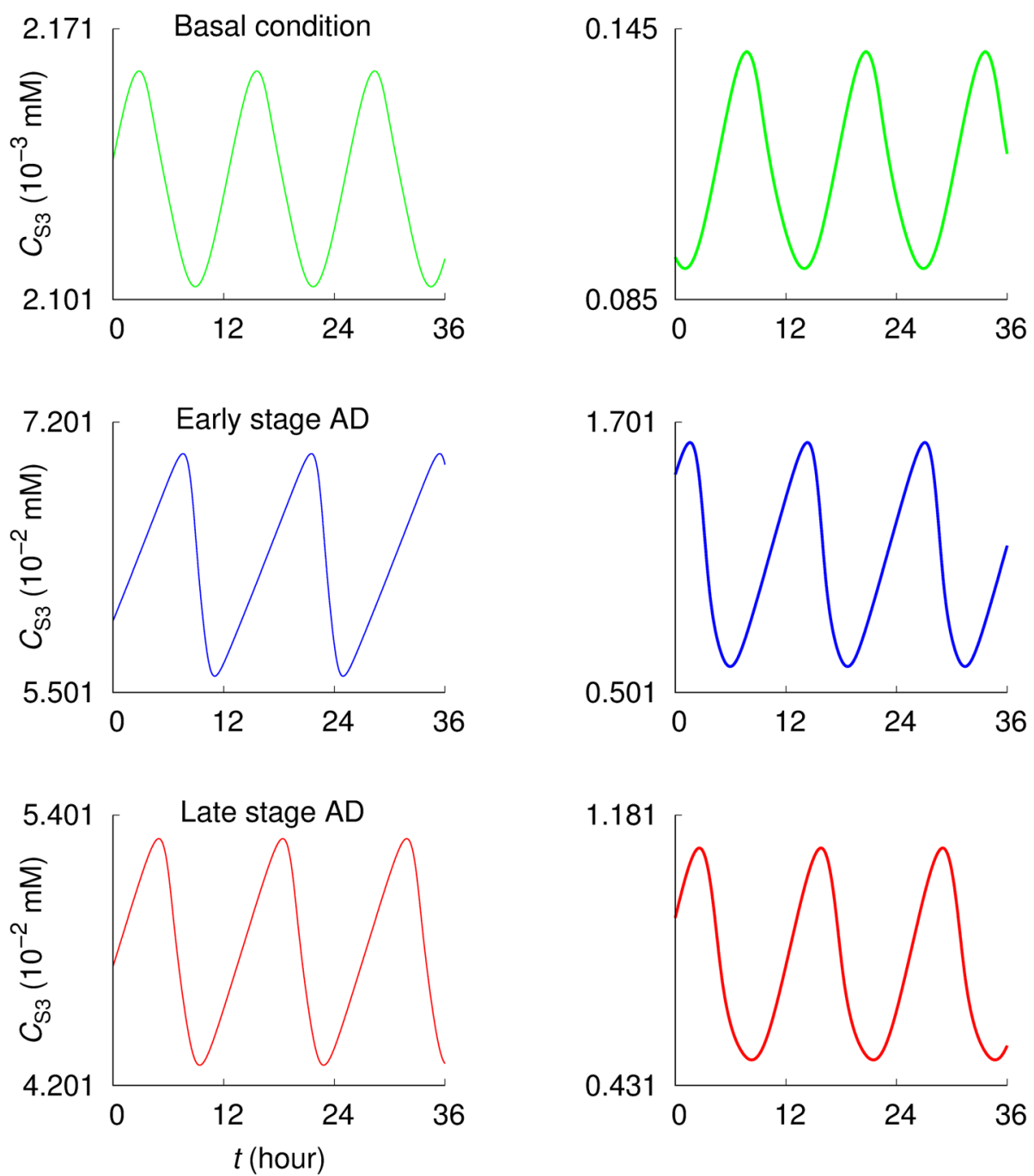

Fig. 3 Intracellular $A \beta$ concentrations under normal and pathological conditions. The intracellular $A \beta$ concentration $C_{S 3}$ displays oscillatory behaviors depending on the parameters. The basal value of $A \beta$ generation rate constant (i.e., $\beta=\beta^{(0)}$ ) has been used for the normal condition while $\beta=100 \times \beta^{(0)}$ has been used for the early stage $A D$. For the late stage $A D$, the specific rate constants of autolysosome formation and intralysosomal hydrolysis have been set equal to $r_{13}=0.1 \times r_{13}{ }^{(0)}$ and $r_{h 3}=0.1 \times r_{h 3}{ }^{(0)}$, retaining the high A generation rate as the early state AD. The results in the second column were obtained under 20-fold increase in the autophagosome formation rate constant $\left(r_{g 3}=20 \times r_{g 3}{ }^{(0)}\right)$ with others the same as those in the first column

the autolysosome concentration $C_{13}$ is increased upon autophagy induction (the second and fourth rows of the second and third columns of Fig. 6). Under the basal condition, the oscillatory patterns of autophagic fluxes and steady-state concentrations of autophagosomes and autolysosomes are not significantly affected by the autophagy induction, compared to the $\mathrm{AD}$ cases.

As shown above, autophagy induction (i.e., $r_{g 3}=20 \times r_{g 3}^{(0)}$ ) significantly reduces $C_{\mathrm{S} 3}$ and $C_{\mathrm{ES} 3}$. Increasing $r_{g 3}$ beyond $20 \times r_{g 3}^{(0)}$ reduces the $\mathrm{A} \beta$ levels further, until they reach basal levels. However, the required value of $r_{g 3}$ to bring the basal levels may vary depending on the stage of $\mathrm{AD}$ and the activities of the other autophagic steps such as autophagosome maturation (i.e., autolysosome formation) and intralysosomal hydrolysis.

Figure 7 presents a three-dimensional surface plot, exhibiting step-specific and combined effects of the autophagy pathway on $A \beta$ levels for a moderately high $A \beta$ formation rate $\beta / \beta^{(0)}=10$ (the first column) and an extremely high formation rate $\beta / \beta^{(0)}=100$ (the second column). The vertical axis measures the autophagosome formation rate relative to its normal value (i.e., $r_{g 3} / r_{g 3}{ }^{(0)}$ ) 


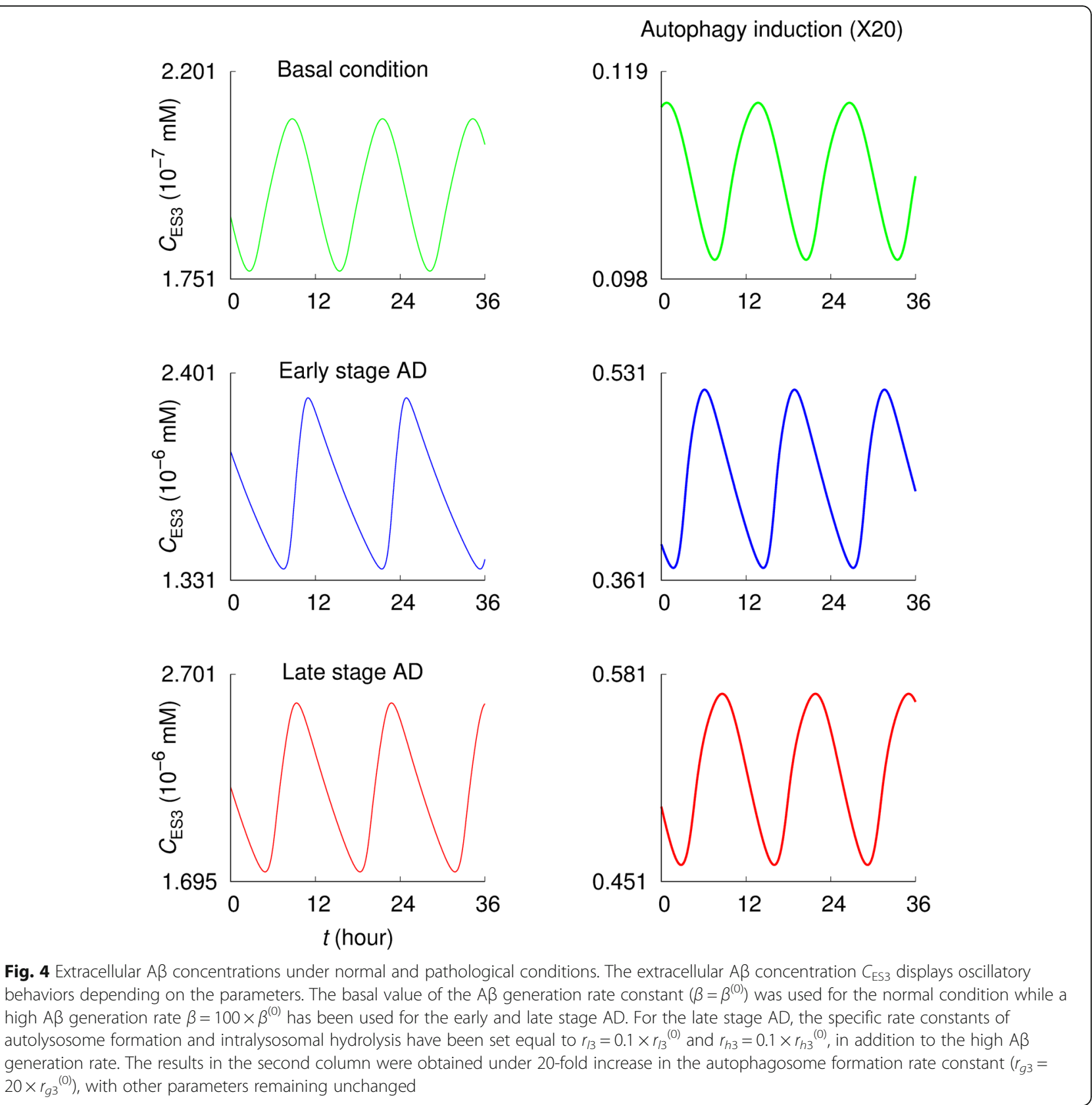

and the two horizontally placed axes represent the autolysosome formation and the intralysosomal hydrolysis rates relative to the normal values, spanning the range from highly induced activity $\left(r_{l 3} / r_{l 3}{ }^{(0)}=r_{h 3} / r_{h 3}{ }^{(0)}=30\right)$ to normal $\left(r_{l 3} / r_{l 3}{ }^{(0)}=r_{h 3} / r_{h 3}{ }^{(0)}=1\right)$ and extremely reduced activity $\left(r_{l 3} / r_{l 3}{ }^{(0)}=r_{h 3} / r_{h 3}{ }^{(0)}=0.1\right)$. The surfaces designate time-averaged intracellular $\mathrm{A} \beta$ concentration $\left\langle C_{\mathrm{S} 3}\right\rangle$ (top) and extracellular $\mathrm{A} \beta$ concentration $\left\langle C_{\mathrm{ES} 3}\right\rangle$ (bottom) for basal parameter values (i.e., under normal conditions); regions above and below the surface correspond to $A \beta$ concentrations lower and higher than the basal values, respectively.
For both $\mathrm{A} \beta$ synthesis rates $\left(\beta / \beta^{(0)}=10\right.$ and 100), $\left\langle C_{\mathrm{S} 3}\right\rangle$ and $\left\langle C_{\mathrm{ES} 3}\right\rangle$ decrease with $r_{g 3}$ in a log-normal manner, $C_{r_{g 3} / r_{g 3}^{(0)}=x}=\left(\frac{\gamma}{x \sigma \sqrt{2 \pi}}\right) \exp \left[-(\log x-\mu)^{2} / 2 \sigma^{2}\right]$, where $\langle C\rangle$ denotes $\left\langle C_{\mathrm{S} 3}\right\rangle$ or $\left\langle C_{\mathrm{ES} 3}\right\rangle$ and $\gamma, \sigma$, and $\mu$ are adjustable parameters (Fig. 8). When $r_{l 3}$ is decreased from 1 to 0.1, $\left\langle C_{\mathrm{S} 3}\right\rangle$ decreases while $\left\langle C_{\mathrm{ES} 3}\right\rangle$ increases. In contrast, when $r_{l 3}>1$, the concentrations are relatively independent of $r_{l 3}$. The effects of $r_{h 3}$ generally follow the trend.

The surface shape of Fig. 7 reflects the combined effects of the three-autophagy steps. A greater vale of $r_{g 3}$ is required to return to basal values in the case $\beta / \beta^{(0)} \stackrel{g}{=}$ 

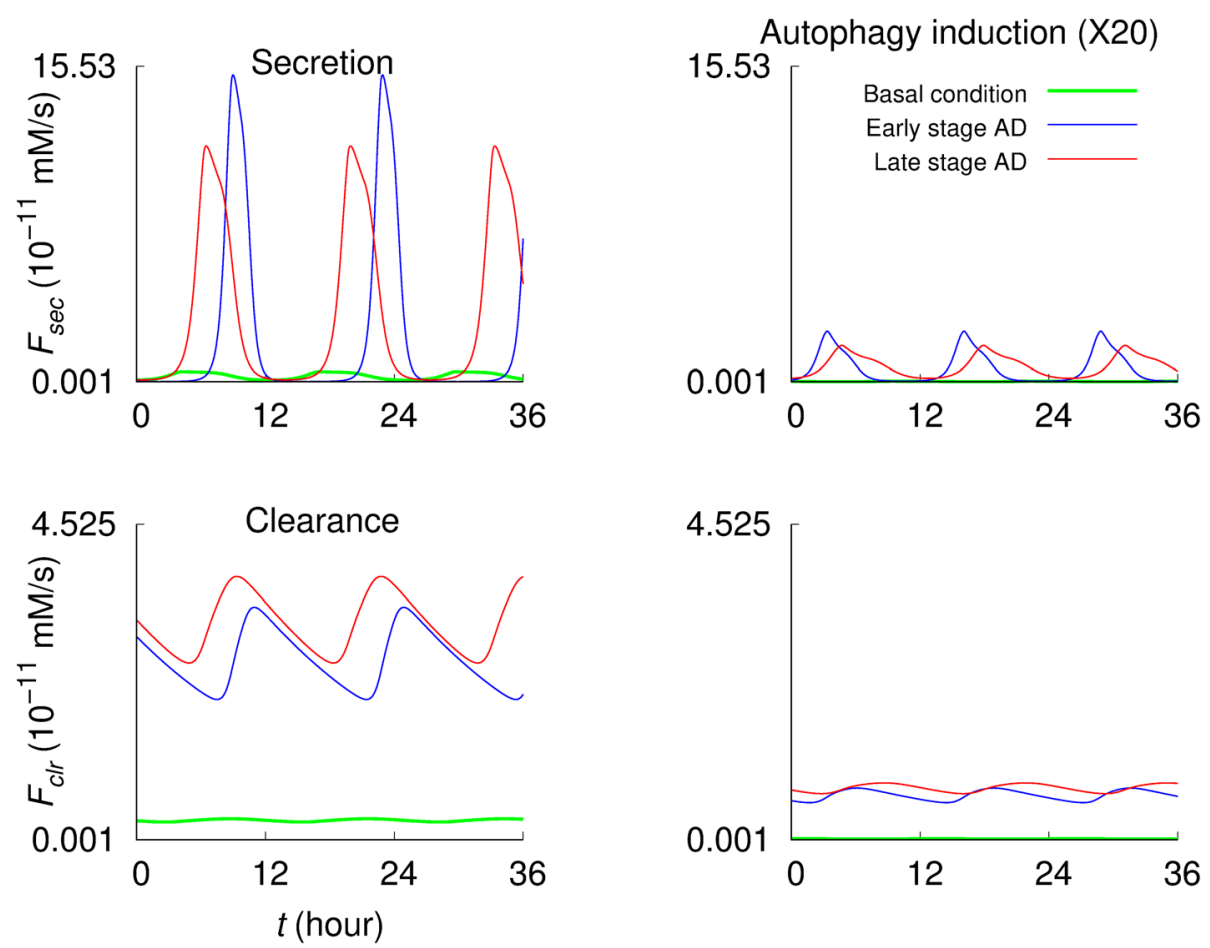

Fig. $5 \mathrm{~A} \beta$ secretion and clearance fluxes in normal and pathological conditions. $F_{\text {sec }}$ and $F_{c l r}$ denote the $A \beta$ secretion flux (from the intracellular to the extracellular space) and $A \beta$ clearance flux in the extracellular space, respectively. The results in the second column have been obtained under 20-fold increase in the autophagosome formation rate constant $\left(r_{g 3}=20 \times r_{g 3}{ }^{\left({ }^{(0)}\right.}\right)$, with other parameters kept unchanged

100 compared with the case $\beta / \beta^{(0)}=10$. At $r_{l 3} / r_{l 3}{ }^{(0)}<1$ and $r_{h 3} / r_{h 3}{ }^{(0)}<1$ both concentrations change greatly compared with the case $r_{l 3} / r_{l 3}{ }^{(0)}>1$ and $r_{h 3} / r_{h 3}{ }^{(0)}>1$, indicating that reduction of autolysosome formation and/ or intralysosomal hydrolysis has greater impact on the $\mathrm{A} \beta$ concentrations than promotion of these steps. Above $r_{h 3} / r_{h 3}{ }^{(0)}=\sim 45.2\left(\right.$ for $\left.\beta / \beta^{(0)}=10\right)$ and $r_{h 3} / r_{h 3}{ }^{(0)}=\sim 11.1$ (for $\left.\beta / \beta^{(0)}=100\right)$, the oscillations of proteins $\left(C_{\mathrm{S} 1}, C_{\mathrm{S} 2}\right.$, $C_{\mathrm{S} 3}$, and $\left.C_{\mathrm{ES} 3}\right)$, ATP $\left(C_{\mathrm{A}}\right)$, and amino acids $\left(C_{\mathrm{a}}\right)$ disappear, converging to stationary values (green surfaces in Figs. 7 and 9). In the stationary region, the effects of $r_{l 3} / r_{l 3}{ }^{(0)}$ and $r_{h 3} / r_{h 3}{ }^{(0)}$ are minimal, as manifested by the flatness of the green surface.

\section{Discussion}

In this study we have investigated via modeling and simulations how autophagy activity affects $A \beta$ kinetics such as the intra and extracellular levels, secretion, clearance, and autophagic degradation. The mathematical model has been extended from the multi-compartment autophagy model originally developed by Han and Choi $[4,9,49$, $50]$ to the one with $A \beta$ kinetics incorporated by accommodating the current working hypothesis [29-31] and the experimental mechanistic studies $[28-36,51]$ on the relationship between autophagy activity and $A \beta$ kinetics. Such multi-compartment frameworks $[4,9,49,50]$ are especially useful for testing biological hypotheses regarding the selective autophagy including Aggrephagy (i.e., autophagic degradation of protein aggregates), Mitophagy (for mitochondria), and Xenophagy (for microbes) [54] because the model can be easily modified easily to incorporate new substrates for selective degradation in each compartment (see Fig. 1). This approach can be further improved by including detailed mathematical descriptions of autophagyrelated cellular signaling pathways, which have been extensively explored in recent years [55-59].

The analysis began with the profiles of $A \beta$ fluxes governing the intracellular and extracellular $A \beta$ concentrations under the normal conditions. As shown in Fig. 2, the intracellular $A \beta$ concentration is determined by the difference between influx (i.e., $\mathrm{A} \beta$ generation flux) and efflux rates of autophagic sequestration, non-autophagic degradation, and $A \beta$ secretion, while the extracellular $A \beta$ concentration is governed by $A \beta$ secretion and clearance. This provides an overview of the system-how the $A \beta$ levels might be determined, giving the idea of how to maintain normal A $\beta$ levels against pathological conditions. Promoting autophagic sequestration flux (i.e., autophagy induction) would significantly reduce the intracellular and extracellular $\mathrm{A} \beta$ concentrations for the early and the late stage AD (Figs. 3 and 4). Interestingly, the intracellular concentration is higher in early stage than late stage $\mathrm{AD}$, while extracellular concentration is higher in late stage $\mathrm{AD}$. $\mathrm{A} \beta$ secretion and clearance fluxes are promoted in the early and late stage 

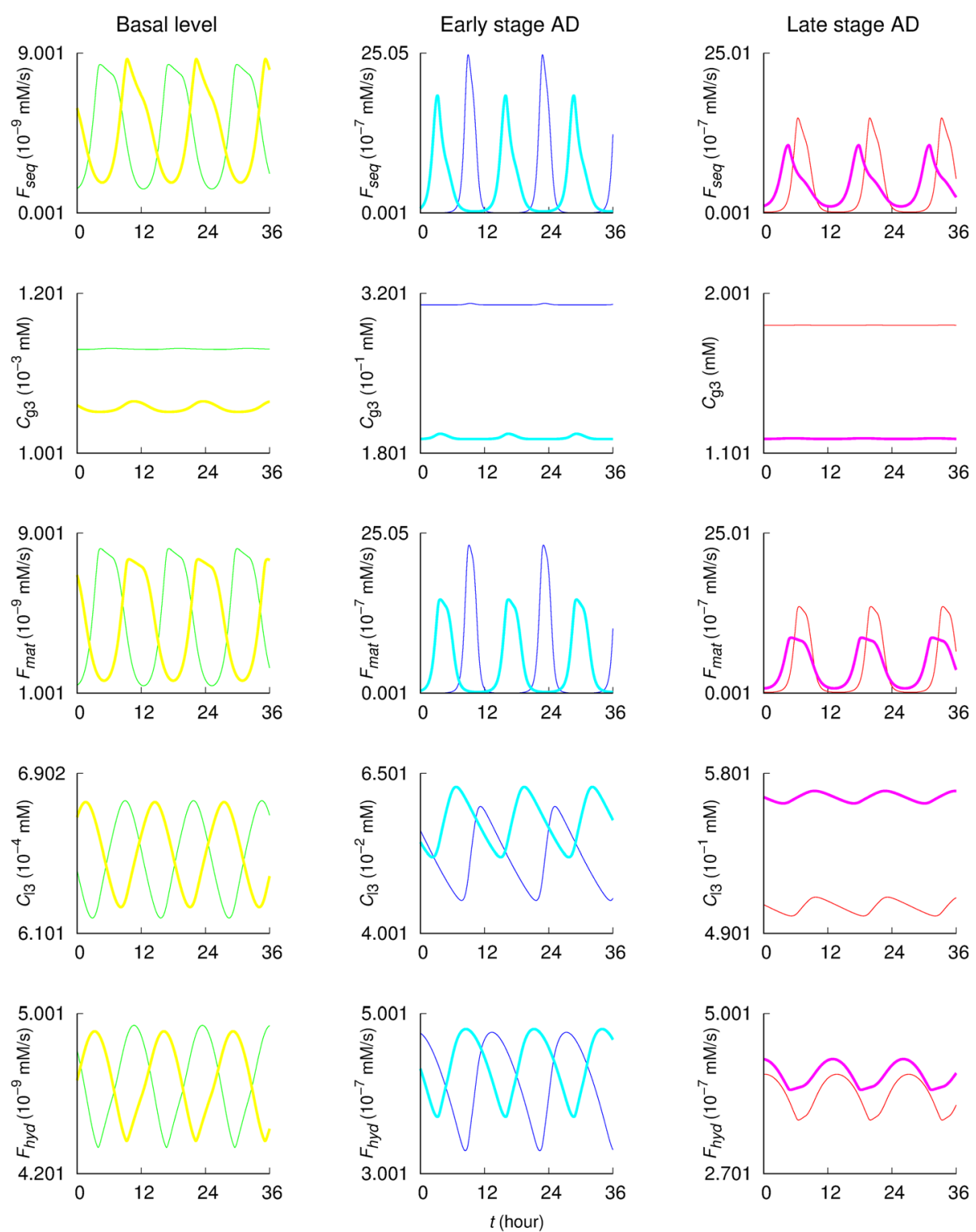

Fig. 6 Dynamics of autophagy. $F_{\text {seq, }} F_{\text {mat }}$, and $F_{\text {hyd }}$ denote fluxes of protein sequestration (i.e., autophagosome formation), autophagosome maturation (i.e., autolysosome formation), and intralysosomal hydrolysis steps, respectively. $C_{\mathrm{g} 3}$ and $C_{13}$ are the autophasosome and autolysosome concentrations in $A \beta$, respectively. Yellow, cyan, and purple lines plot results of autophagy induction (i.e., $\left.r_{g 3}=20 \times r_{g 3}{ }^{(0)}\right)$ in the cases of the basal condition, early stage $A D$, and late stage $A D$, respectively. Green, blue, and red lines plot results from simulations with $r_{g 3}{ }^{(0)}$ in the same three cases (basal, early stage $A D$, and late stage $A D$ ), respectively

AD compared to the normal condition (Fig. 5). In both pathological conditions, promoting autophagic sequestration efficiently decreases the $A \beta$ secretion and clearance fluxes.

In the examination of autophagy dynamics under normal and pathological conditions (Fig. 6), the autophagic fluxes and the concentrations of autophagosome $\left(C_{\mathrm{g} 3}\right)$ and autolysosome $\left(C_{13}\right)$ in both early and late stage $\mathrm{AD}$ are significantly increased than in the basal condition. $C_{\mathrm{g} 3}$ and $C_{13}$ are about ten times greater in late stage AD than in early stage AD. This implies that at the late stage
AD the increased concentrations due to reduced maturation and intralysosomal hydrolysis may clog neurons, which would further reduce the autophagic A $\beta$ degradation efficacy. Under normal conditions the basal autophagy level is sufficient for removing intracellular $A \beta$ as the mTOR activity is tightly regulated. However, during early and late stage of $\mathrm{AD}$, an increase in soluble $\mathrm{A} \beta$ levels leads to mTOR hyperactivity, which should in turn suppress autophagosome formation (i.e., reduced A $\beta$ sequestration) (for details see Autophagosome formation in Mathematical model). Reduced autophagosome 

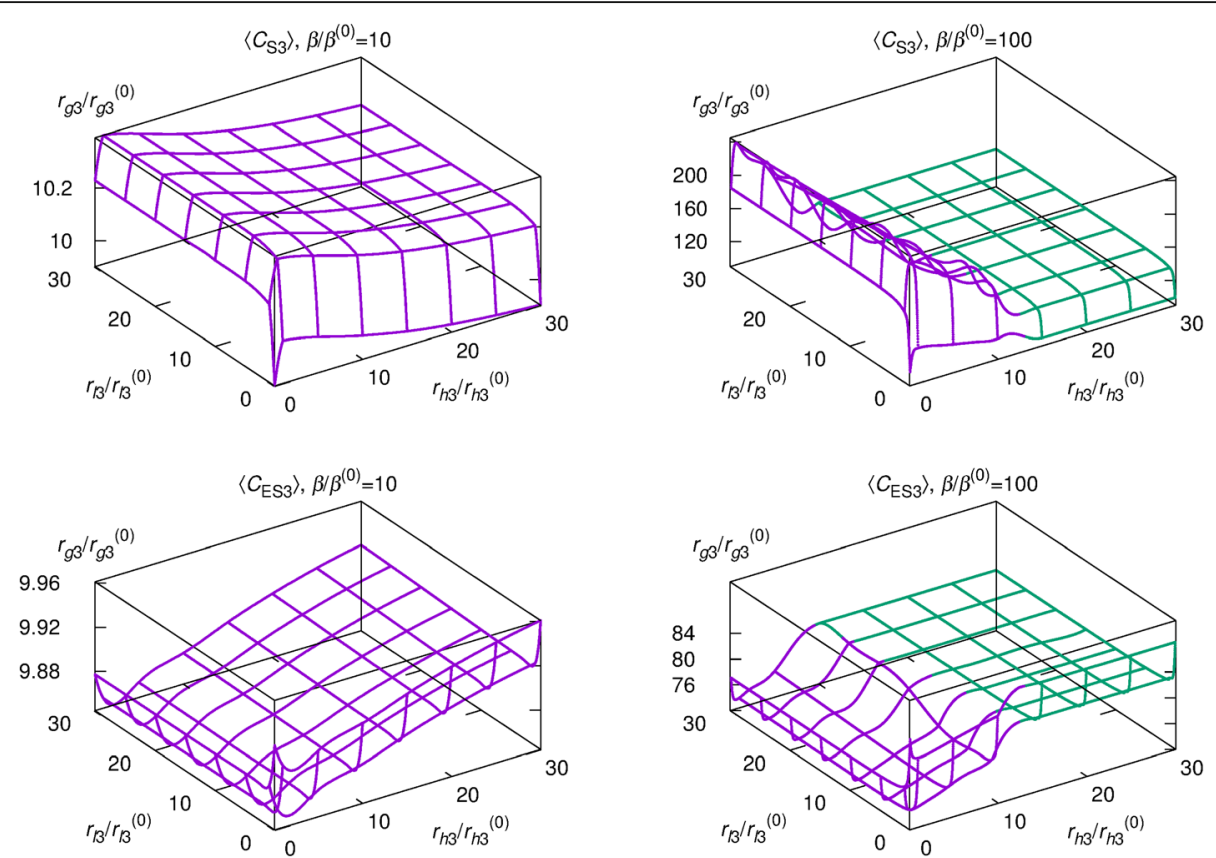

Fig. 7 A $\beta$ concentrations depending upon activities of three autophagy steps. The surfaces specify time-averaged intracellular $A \beta$ concentration $\left\langle C_{S 3}\right\rangle$ (first row) and extracellular $A \beta$ concentration $\left\langle C_{E S 3}\right\rangle$ (second row) for basal parameter values; regions above and below the surfaces correspond to $A \beta$ concentrations lower and higher than the basal values. The first and the second columns correspond to $\beta / \beta^{(0)}=10$ and $\beta /$ $\beta^{(0)}=100$, respectively. Computations were performed with $r_{13} / r_{13}{ }^{(0)}$ and $r_{h 3} / r_{h 3}{ }^{(0)}$ varied in increments and the mixed cubic and quintic spline interpolation applied. On the surfaces in purple the A $\beta$ concentrations display oscillations while oscillations are absent on the green surfaces
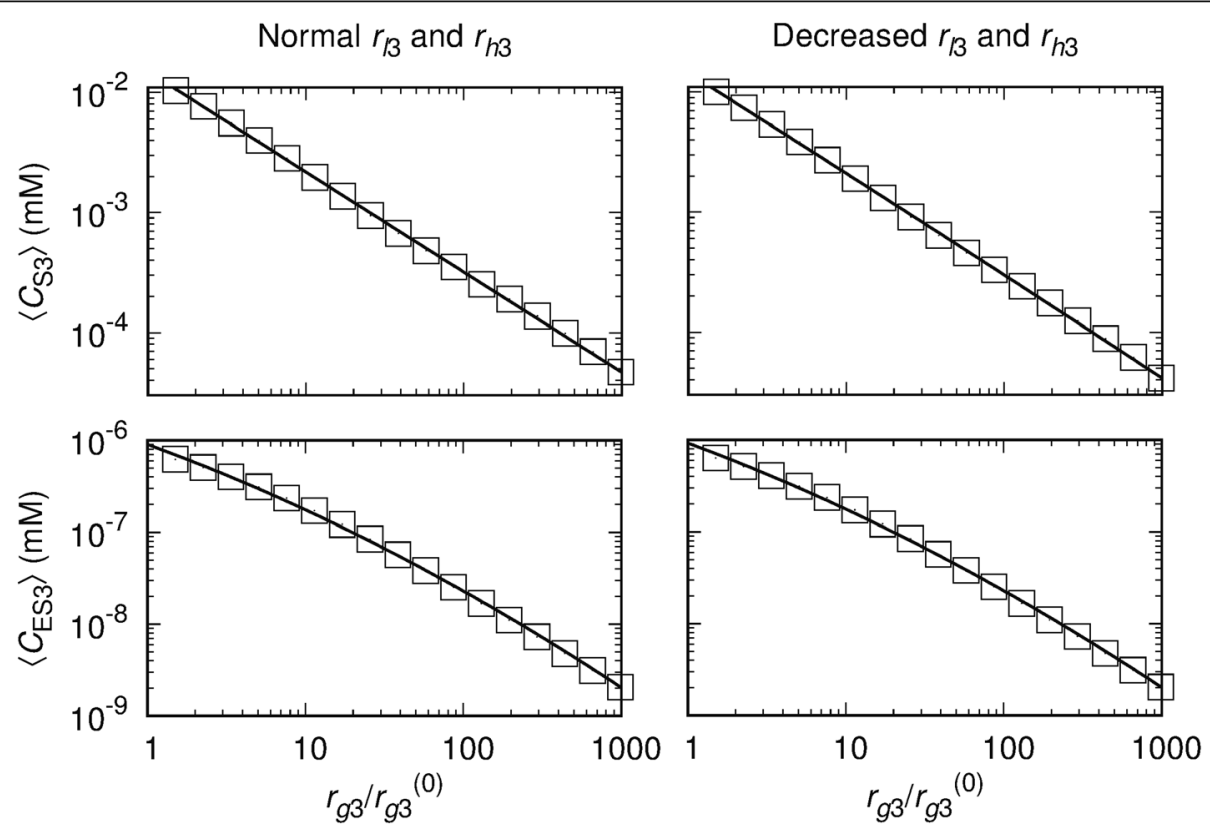

Fig. 8 Log-normal relations between average $A \beta$ concentrations and $r_{g 3} / r_{g 3}{ }^{(0)}$. Log-log plots of $\left\langle C_{53}\right\rangle$ (top) and $\left\langle C_{E S 3}\right\rangle$ (bottom) versus $r_{g 3} / r_{g 3}{ }^{(0)}$ for $r_{13} / r_{/ 3}{ }^{(0)}=r_{h 3} / r_{h 3}{ }^{(0)}=1$ (left column) and 0.1 (right column). Data were obtained at $\beta / \beta^{(0)}=10$. Squares indicate average values obtained via simulations and lines depict the least square fit of the log-normal relation 


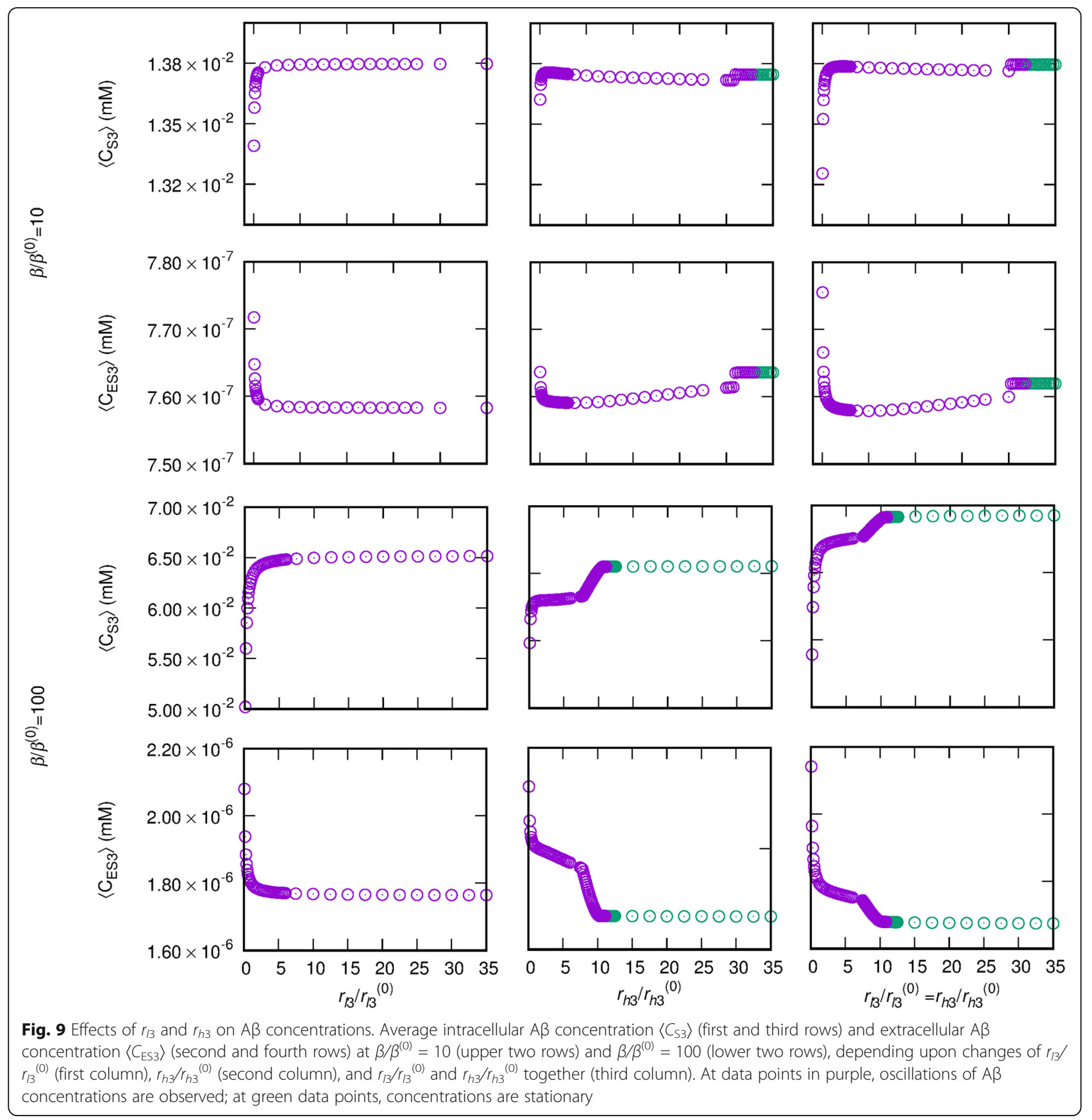

formation would increase further the $A \beta$ levels, creating a vicious cycle.

The influence of each autophagic step on the intracellular and the extracellular $\mathrm{A} \beta$ concentrations $\left(C_{\mathrm{S} 3}\right.$ and $\left.C_{\mathrm{ES} 3}\right)$ was examined, providing insight into disease and potential effects of drugs targeting specific steps in the autophagic pathway. The autophagosome formation activity plays a significant role in regulating average values of $C_{\mathrm{S} 3}$ and $C_{\mathrm{ES} 3}$ via a log-normal relation: promoting the autophagosome formation step decreases both $A \beta$ levels. As the autolysosome formation and intralysosomal hydrolysis rates are decreased, as expected in late stage $\mathrm{AD}, C_{\mathrm{S} 3}$ decreases but $C_{\mathrm{ES} 3}$ increases. It is thus disclosed that the progress from early to late stage $\mathrm{AD}$ leads to higher $C_{\mathrm{ES} 3}$ levels, which could contribute to the deposition of extracellular plaques. On the other hand, $C_{\mathrm{S} 3}$ decreases along the pathway to late stage $\mathrm{AD}$ (i.e., autophagic $\mathrm{A} \beta$ degradation is defective in addition to the increased $A \beta$ generation).

The model has reproduced successfully the oscillatory behavior of autophagy activity concerning the autophagyrelated fluxes and the concentrations of $A \beta$, autophagosomes, and autolysosomes (Figs. 2-6). Such simulated 
"autophagy oscillations" are qualitatively similar to those observed in biological experiments [60-69]. However, mechanisms underlying the phenomena have only begun to be explored [68-70]. For instance, the oscillations might be tightly controlled via the autophagy-related signaling pathways to keep the autophagy activity within physiological levels that is important for cellular homeostasis. The simulation results presented here exhibit two interesting features: 1 ) In the early- and late-stage $\mathrm{AD}$, oscillations of $\mathrm{C}_{\mathrm{S} 3}$ and $\mathrm{C}_{\mathrm{ES} 3}$ exhibit asymmetric patterns while they are symmetric under the basal condition. 2) Above certain activity levels of autolysosome formation (measured by $r_{l 3}$ ) and intralysosomal hydrolysis $\left(r_{h 3}\right)$ for $\mathrm{A} \beta$, there disappear oscillations of proteins $\left(C_{\mathrm{S} 1}, C_{\mathrm{S} 2}, C_{\mathrm{S} 3}\right.$, and $\left.\mathrm{C}_{\mathrm{ES} 3}\right)$, ATP $\left(\mathrm{C}_{\mathrm{A}}\right)$, and amino acids $\left(\mathrm{C}_{\mathrm{a}}\right)$.

These findings are expected to be useful for the design of future studies and may give insight to maintaining physiological regulation of the $A \beta$ levels. Defects arising in different steps of the autophagy process would influence in a different way the $A \beta$ kinetics, which will give rise to distinct AD pathology. This suggests that pharmacological modulations of the different autophagy steps may have different implications for AD therapy and prevention.

\section{Conclusions}

A mathematical model of autophagy and $A \beta$ metabolism has been developed by integrating experimental knowledge of individual mechanisms. It has been observed that the different steps of the autophagy pathway have different effects on the $A \beta$ levels. Promotion of $A \beta$ sequestration has led to a reduction of both intracellular and extracellular $A \beta$, while suppression of autophagosome maturation and intralysosomal hydrolysis has had opposing effects, increasing intracellular and decreasing extracellular $\mathrm{A} \beta$. The model thus predicts that modulations of different steps have significant step-specific and combined effects on $A \beta$ levels, suggesting therapeutic and preventive implications of autophagy on AD.

\section{Methods}

A mathematical model is developed to examine roles of autophagy in modulating $A \beta$ kinetics. The model includes a nonlinear relationship between autophagy activity and intracellular and extracellular $A \beta$ levels. Autophagy degrades intracellular $A \beta$ and influences the $A \beta$ secretion from the inside to the outside of the neuron (i.e., extracellular space) and the concentration-dependent biphasic $A \beta$ clearance in the extracellular space. Conversely, the intracellular $A \beta$ level regulates the autophagy induction step (i.e., autophagosome formation or protein sequestration). The dynamics of these relations are described by twelve coupled differential equations which are solved via the 5th order Runge-Kutta method for very high precision. Mixed spline interpolation has been used to produce the three-dimensional surface plots of the $\mathrm{A} \beta$ concentrations.

\section{Acknowledgements}

The authors thank James Anderson for helpful discussion. The Linux cluster at the Theory Group for Emergence and Complexity (http://tec.snu.ac.kr) was employed.

\section{Authors' contributions}

$\mathrm{KH}$ and MYC designed the study. KH and SHK performed the computations. All participated in the analysis and interpretation of the results and wrote the manuscript.

\section{Funding}

K.H. acknowledges support by the Intramural Research Program of the NIH, National Heart, Lung and Blood Institute. K.H. was supported in part by a grant from the KRIBB Research Initiative Program (Korean Biomedical Scientist Fellowship Program), Korea Research Institute of Bioscience and Biotechnology, Republic of Korea. MYC acknowledges support from the National Research Foundation of Korea through the Basic Science Research Program (Grant No. 2019R1F1A1046285).

\section{Availability of data and materials}

Not applicable.

Ethics approval and consent to participate

Not applicable.

\section{Consent for publication}

Not applicable.

\section{Competing interests}

The authors declare that they have no competing interests.

Received: 19 December 2019 Accepted: 11 February 2020

Published online: 26 February 2020

\section{References}

1. de Reuck AVS. CM: Ciba Foundation Symposium on Lysosomes. London: J.A. Churchill Ltd; 1963.

2. Mizushima N, Komatsu M. Autophagy: renovation of cells and tissues. Cell. 2011;147:728-41.

3. Klionsky DJ, Emr SD. Autophagy as a regulated pathway of cellular degradation. Science (New York, NY). 2000;290:1717-21.

4. Han K, Kim J, Choi M. Autophagy mediates phase transitions from cell death to life. Heliyon. 2015;1:e00027.

5. Levine B, Kroemer G. Biological functions of autophagy genes: a disease perspective. Cell. 2019;176:11-42.

6. Jewell JL, Russell RC, Guan K-L. Amino acid signalling upstream of mTOR. Nat Rev Mol Cell Biol. 2013;14:133-9.

7. Liang J, Shao SH, Xu Z-X, Hennessy B, Ding Z, Larrea M, Kondo S, Dumont DJ, Gutterman JU, Walker $C L$, et al. The energy sensing LKB1-AMPK pathway regulates p27kip1 phosphorylation mediating the decision to enter autophagy or apoptosis. Nat Cell Biol. 2007;9:218.

8. Hardie DG. AMP-activated protein kinase: an energy sensor that regulates all aspects of cell function. Genes Dev. 2011;25:1895-908.

9. Han K, Kwon HW, Kang H, Kim J, Lee M-S, Choi MY. Dynamics of macroautophagy: modeling and oscillatory behavior. Physica A. 2012;391: 686-92.

10. Menzies FM, Fleming A, Caricasole A, Bento CF, Andrews SP, Ashkenazi A, Füllgrabe J, Jackson A, Jimenez Sanchez M, Karabiyik C, et al. Autophagy and Neurodegeneration: pathogenic mechanisms and therapeutic opportunities. Neuron. 2017;93:1015-34.

11. Nixon RA. The role of autophagy in neurodegenerative disease. Nat Med. 2013;19:983.

12. Towers CG, Thorburn A. Therapeutic targeting of autophagy. EBioMedicine. 2016;14:15-23.

13. Boland B, Kumar A, Lee S, Platt FM, Wegiel J, Yu WH, Nixon RA. Autophagy induction and Autophagosome clearance in neurons: relationship to Autophagic pathology in Alzheimer's disease. J Neurosci. 2008;28:6926-37.

14. Lee S, Sato Y, Nixon RA. Lysosomal proteolysis inhibition selectively disrupts axonal transport of Degradative organelles and causes an Alzheimer's-like axonal dystrophy. J Neurosci. 2011;31:7817-30. 
15. Komatsu M, Waguri S, Chiba T, Murata S, Iwata J-I, Tanida I, Ueno T, Koike M, Uchiyama Y, Kominami E, Tanaka K. Loss of autophagy in the central nervous system causes neurodegeneration in mice. Nature. 2006;441:880.

16. Hara T, Nakamura K, Matsui M, Yamamoto A, Nakahara Y, Suzuki-Migishima R, Yokoyama M, Mishima K, Saito I, Okano H, Mizushima N. Suppression of basal autophagy in neural cells causes neurodegenerative disease in mice. Nature. 2006:441:885

17. Lee JW, Nam H, Kim LE, Jeon Y, Min H, Ha S, et al. TLR4 (toll-like receptor 4) activation suppresses autophagy through inhibition of FOXO3 and impairs phagocytic capacity of microglia. Autophagy. 2019:15:753-70.

18. Conway O, Akpinar HA, Rogov W, Kirkin V: Selective Autophagy Receptors in Neuronal Health and Disease. J Mol Biol 2019. In Press. https://doi.org/10. 1016/j.jmb.2019.10.013

19. Zaffagnini G, Martens S. Mechanisms of selective autophagy. J Mol Biol. 2016:428:1714-24

20. Reggiori F, Komatsu M, Finley K, Simonsen A. Autophagy: more than a nonselective pathway. Int J Cell Biol. 2012;2012.

21. Kraft C, Peter M, Hofmann K. Selective autophagy: ubiquitin-mediated recognition and beyond. Nat Cell Biol. 2010;12:836-41.

22. Johansen T, Lamark T. Selective autophagy mediated by autophagic adapter proteins. Autophagy. 2011;7:279-96.

23. Fotuhi M, Hachinski V, Whitehouse PJ. Changing perspectives regarding late-life dementia. Nat Rev Neurol. 2009:5:649.

24. Alzheimer's Association. 2018 Alzheimer's disease facts and figures. Alzheimers Dement. 2018;14:367-429.

25. Hardy J, Selkoe DJ. The amyloid hypothesis of Alzheimer's disease: Progress and problems on the road to therapeutics. Science. 2002;297:353-6.

26. Hardy J, Duff K, Hardy KG, Perez-Tur J, Hutton M. Genetic dissection of Alzheimer's disease and related dementias: amyloid and its relationship to tau. Nat Neurosci. 1998;1:355.

27. Kayed R, Lasagna-Reeves CA. Molecular mechanisms of amyloid oligomers toxicity. J Alzheimers Dis. 2013;33:S67-78.

28. Oddo S. The role of mTOR signaling in Alzheimer disease. Front Biosci. 2012; 4:941-52.

29. Nilsson P, Loganathan K, Sekiguchi M, Matsuba Y, Hui K, Tsubuki S, et al. A secretion and plaque formation depend on autophagy. Cell Rep. 2013;5:619.

30. Nilsson P, Sekiguchi M, Akagi T, Izumi S, Komori T, Hui K, et al. Autophagyrelated protein 7 deficiency in amyloid $\beta(A \beta)$ precursor protein transgenic mice decreases $A \beta$ in the multivesicular bodies and induces $A \beta$ accumulation in the Golgi. Am J Pathol. 2015;185:305-13.

31. Nilsson P, Saido TC. Dual roles for autophagy: degradation and secretion of Alzheimer's disease A $\beta$ peptide. BioEssays : news and reviews in molecular, cellular and developmental biology. 2014;36:570-8.

32. Bhaskar K, Miller M, Chludzinski A, Herrup K, Zagorski M, Lamb BT. The PI3KAkt-mTOR pathway regulates $A \beta$ oligomer induced neuronal cell cycle events. Mol Neurodegener. 2009;4:14

33. Wang C, Yu J-T, Miao D, Wu Z-C, Tan M-S, Tan L. Targeting the mTOR signaling network for Alzheimer's disease therapy. Mol Neurobiol. 2014:49:120-35.

34. Caccamo A, Majumder S, Richardson A, Strong R, Oddo S. Molecular interplay between mammalian target of rapamycin (mTOR), amyloid-beta, and tau: effects on cognitive impairments. J Biol Chem. 2010;285:13107-20.

35. Yuede CM, Lee H, Restivo JL, Davis TA, Hettinger JC, Wallace CE, et al. Rapid in vivo measurement of $\beta$-amyloid reveals biphasic clearance kinetics in an Alzheimer's mouse model. J Exp Med. 2016;213:677-85.

36. Mawuenyega KG, Sigurdson W, Ovod V, Munsell L, Kasten T, Morris JC, et al. Decreased clearance of CNS $\beta$-amyloid in Alzheimer's disease. Science. 2010; 330:1774.

37. Pfeifer U. Inhibition by insulin of the formation of autophagic vacuoles in rat liver. A morphometric approach to the kinetics of intracellular degradation by autophagy. J Cell Biol. 1978;78:152-67.

38. Schworer CM, Shiffer KA, Mortimore GE. Quantitative relationship between autophagy and proteolysis during graded amino acid deprivation in perfused rat liver. J Biol Chem. 1981;256:7652-8.

39. Kovács J, Fellinger E, Kárpáti AP, Kovács AL, László L, Réz G. Morphometric evaluation of the turnover of autophagic vacuoles after treatment with triton $\mathrm{X}-100$ and vinblastine in murine pancreatic acinar and seminal vesicle epithelial cells. Virchows Archiv B. 1987;53:183.

40. Plomp PJ, Gordon PB, Meijer AJ, Høyvik H, Seglen PO. Energy dependence of different steps in the autophagic-lysosomal pathway. J Biol Chem. 1989; 264:6699-704
41. Plomp PJ, Wolvetang EJ, Groen AK, Meijer AJ, Gordon PB, Seglen PO. Energy dependence of autophagic protein degradation in isolated rat hepatocytes. Eur J Biochem. 1987;164:197-203.

42. Seglen PO, Gordon PB. Amino acid control of autophagic sequestration and protein degradation in isolated rat hepatocytes. J Cell Biol. 1984;99:435-44.

43. Lee J-Y, Yao T-P. Quality control autophagy: a joint effort of ubiquitin, protein deacetylase and actin cytoskeleton. Autophagy. 2010;6:555-7.

44. Behrends C, Fulda S. Receptor proteins in selective autophagy. Int J Cell Biol. 2012;2012:673290.

45. Kuma A, Mizushima N. Physiological role of autophagy as an intracellular recycling system: with an emphasis on nutrient metabolism. Semin Cell Dev Biol. 2010;21:683-90.

46. Mortimore GE, Pösö AR. Intracellular protein catabolism and its control during nutrient deprivation and supply. Annu Rev Nutr. 1987;7:539-68.

47. Yoshimori T. Autophagy: a regulated bulk degradation process inside cells. Biochem Biophys Res Commun. 2004;313:453-8.

48. Mizushima N, Yamamoto A, Matsui M, Yoshimori T, Ohsumi Y. In vivo analysis of autophagy in response to nutrient starvation using transgenic mice expressing a fluorescent autophagosome marker. Mol Biol Cell. 2004;15:1101-11.

49. Han K, Kim J, Choi M. Computer simulations unveil the dynamics of autophagy and its implications for the cellular quality control. J Biol Syst. 2014;22:659-75.

50. Han K, Kim J, Choi MY. Quantitative indices of autophagy activity from minimal models. Theor Biol Med Model. 2014;11:31.

51. Bateman RJ, Munsell LY, Morris JC, Swarm R, Yarasheski KE, Holtzman DM. Human amyloid- $\beta$ synthesis and clearance rates as measured in cerebrospinal fluid in vivo. Nat Med. 2006;12:856.

52. Seglen PO, Solheim AE. Effects of aminooxyacetate, alanine and other amino acids on protein synthesis in isolated rat hepatocytes. Biochim Biophys Acta. 1978;520:630-41.

53. Seglen PO, Bohley P. Autophagy and other vacuolar protein degradation mechanisms. Experientia. 1992:48:158-72.

54. Klionsky DJ, Cuervo AM, Dunn JWA, Levine B, van der Klei IJ, Seglen PO. How shall I eat thee? Autophagy. 2007;3:413-6.

55. Tavassoly I, Parmar J, Shajahan-Haq AN, Clarke R, Baumann WT, Tyson $J$ J. Dynamic modeling of the interaction between autophagy and apoptosis in mammalian cells. CPT Pharmacometrics Syst Pharmacol. 2015:4:263-72.

56. Tavassoly I. Mathematical Modeling of the Interplay of Autophagy and Apoptosis. In: Tavassoly I, editor. Dynamics of Cell Fate Decision Mediated by the Interplay of Autophagy and Apoptosis in Cancer Cells. Cham: Springer Int Publishing; 2015: p. 23-41.

57. Kapuy O, Vinod PK, Mandl J, Bánhegyi G. A cellular stress-directed bistable switch controls the crosstalk between autophagy and apoptosis. Mol BioSyst. 2013;9:296-306.

58. Jin H, Lei J. A hybrid model of molecular regulation and population dynamics for yeast autophagy. J Theor Biol. 2016;402:45-53.

59. Liu B, Oltvai ZN, Bayır H, Silverman GA, Pak SC, Perlmutter DH, Bahar I. Quantitative assessment of cell fate decision between autophagy and apoptosis. Sci Rep. 2017;7:17605.

60. Ma D, Panda S, Lin JD. Temporal orchestration of circadian autophagy rhythm by C/EBPß. EMBO J. 2011;30:4642-51.

61. Pfeifer $\mathrm{U}$, Scheller $\mathrm{H}$. A morphometric study of cellular autophagy including diurnal variations in kidney tubules of normal rats. J Cell Biol. 1975;64:608-21.

62. Pfeifer U, Strauss P. Autophagic vacuoles in heart muscle and liver. A comparative morphometric study including circadian variations in meal-fed rats. J Mol Cell Cardiol. 1981;13:37-49.

63. Remé CE, Sulser M. Diurnal variation of autophagy in rod visual cells in the rat. Albrecht Von Graefes Arch Klin Exp Ophthalmol. 1977;203:261-70.

64. Pfeifer U. Cellular autophagy and cell atrophy in the rat liver during longterm starvation. Virchows Archiv B. 1972;12:195-211.

65. Sachdeva UM, Thompson CB. Diurnal rhythms of autophagy: implications for cell biology and human disease. Autophagy. 2008:4:581-9.

66. Pfeifer $U$. Inverted diurnal rhythm of cellular autophagy in liver cells of rats fed a single daily meal. Virchows Archiv B. 1972;10:1-3

67. Pfeifer $U$, Bertling J. A morphometric study of the inhibition of autophagic degradation during restorative growth of liver cells in rats re-fed after starvation. Virchows Archiv B. 1977:24:109.

68. Nazio F, Carinci M, Valacca C, Bielli P, Strappazzon F, Antonioli M, Ciccosanti F, Rodolfo C, Campello S, Fimia GM, et al. Fine-tuning of ULK1 mRNA and protein levels is required for autophagy oscillation. J Cell Biol. 2016;215:841-56. 
69. Ryzhikov M, Ehlers A, Steinberg D, Xie W, Oberlander E, Brown S, Gilmore PE, Townsend RR, Lane WS, Dolinay T, et al. Diurnal Rhythms Spatially and Temporally Organize Autophagy. Cell Rep. 2019;26:1880 1892.e1886.

70. Dorvash M, Farahmandnia M, Tavassoly I. A Systems Biology Roadmap to Decode mTOR Control System in Cancer. Interdiscip Sci Comput Life Sci. 2019;12:1-11.

\section{Publisher's Note}

Springer Nature remains neutral with regard to jurisdictional claims in published maps and institutional affiliations.

Ready to submit your research? Choose BMC and benefit from:

- fast, convenient online submission

- thorough peer review by experienced researchers in your field

- rapid publication on acceptance

- support for research data, including large and complex data types

- gold Open Access which fosters wider collaboration and increased citations

- maximum visibility for your research: over $100 \mathrm{M}$ website views per year

At $\mathrm{BMC}$, research is always in progress.

Learn more biomedcentral.com/submissions 